\title{
Formação e Prática Profissional
}

\section{Trabalho apresentado no curso comemorativo dos 100 anos da Faculdade de Odontologia da UFRGS, I2o. Congresso Odontológico Rio-Grandense.} Porto Alegre, 22 a 25 de julho de 1998.

\author{
Eduardo Roberto Corrêa de Barros, CD
}

\section{I.INTRODUÇÃO}

Procurar traduzir algumas preocupações atuais desta mistura do ensino e do trabalho odontológico, é importante porque tem sido pouco freqüente vê-los abordados e discutidos. Pretendo comentar alguns aspectos da nossa atividade profissional (a nossa prática), bem como a formação profissional; que devem ser consentâneas com as aspirações e necessidades odontológicas da nossa população.

A formação e a prática profissionais compreendem um tema de uma vastidão que $e$ a da própria Odontologia, associada a muitas outras áreas do conhecimento de marcada importância . É o que acontece, por exemplo, com as nossas tão conhecidas e importantes química, física, sociologia, engenharia, medicina, ética, pedagogia, psicologia, línguas e artes plásticas dentre tantas outras não menos importantes.

Como para toda a espécie humana, tudo começa com a nossa educação informal, desde o nascimento e pela vida à fora e por toda a vida. Em paralelo, transita pela educação formal: primária, secundária e algum outro curso eventual. 0 desenvolvimento do curso de graduação em Odontologia completa e conclui a nossa formaçāo pré-profissional. Após a formatura, já como profissionais, a nossa formaçāo continua a ocorrer, ao longo de toda a nossa vida; ao longo e em paralelo com a nossa prática profissional. Tais atividades formadoras e reformadoras, evidentemente vão influindo cumulativamente e transformadoramente em nossa prática. E a nossa prática, por sua vez, também vai influindo na quantidade e na qualidade da nossa contínua formação. Um processo desta ordem, tão complexo e afetando a totalidade dos indivíduos que exercem a Odontologia (de maneira direta ou afim ), deveria influir também sobre a própria atividade formadora especifica. Ou seja, deveria influir no ensino daqueles que agora se encontram na etapa da graduação e na da pós. graduação. Para que fique bem claro, a manifestação e ou participação dos CirurgiōesDentistas, poderia e deveria ser um excelente meio de retroalimentação do sistema formador. Isso não vem acontecendo. 0 sistema formador não tem desenvolvido esta prática de se reforçar com seus próprios egressos.

A amplitude do tema, como se percebe, é das maiores e requer uma delimitaçāo e categorização com finalidade didática.

Uma conhecida forma de se trabalhar conteúdos de Odontologia de Saúde Pública, é fazer-se uma análise metodizada dos PROBLEMAS, depois dos RECURSOS e por fim dos MÉTODOS de trabalho. Somente depois da clara definição e quantificação dos problemas é que estamos em condições de passar a analisar os recursos existentes ou disponiveis, para então definir os métodos de trabalho, ou seja, como bem aplicar os recursos na sol ução dos problemas. Isto também pode ser adequado a esta situação.

Vamos nos dedicar, neste trabalho, a analisar problemas da formação e da prática profissional $^{1}$. Não temos a pretensão da cabal delimitação dos problemas, quanto mais a sua perfeita definição. Conseguindo motivar a que algum grupo ligado à formação e ou a prática, se dedique a este estudo, teremos atingido o maior dos objetivos pretendidos.

\section{PROBLEMAS DA FORMAÇÃO PROFISSIONAL,}

Com finalidade metodológica, vamos classificar os problemas da formação profissional em três grupos: de caráter pré-acadêmico,

- de caráter acadêmico e

- de caráter pós-graduado.

\section{Problemas pré-acadêmicos de formação profissional}

Diversos são os problemas de caráter préacadêmico que são capazes de influenciar na formação profissional. Embora não ocorrendo no momento específico da formação profissiona 1 - sendo ate bem precoce a ela - sem dúvida deixam marcas e reflexos capazes de alterá-la profundamente. Alguns exemplos são: - dificuldades de acesso ao ensino primário, ou ao secundário ou ao superior, tendo como causas: a pobreza, o próprio analfabetismo, o desemprego dos pais, a subnutrição....;

-a evasão escolar; a má remuneração dos professores;

- a baixa qualidade do ensino de $1^{\circ} \mathrm{Grau}$; - a baixa qua lidade do ensino de $2^{\circ} \mathrm{Grau}$; - as dificuldades da assistência médicoodontológica ao educando... em suma, todo o conjunto de situaçōes de ordem sócio-econômica que se configuram no grande problema de ordem estrutural do pais e que, se não nos permite atuar como dentistas, requer a nossa atuação cidadã.

\section{Problemas acadêmicos da formação profissional}

Ao nível especifico dos cursos de graduação existem problemas de muitas ordens que periodicamente tem sido mais ou menos considerados. Exemplificando:

- deficiências nos sistemas de avaliaçāo. Alem das deficiências próprias dos sistemas de avaliação, e preciso lembrar da inadequada utilização dos conceitos de avaliação. Todos conhecemos a sistemática dos graus ou notas de zero a dez, ainda em uso em muitas instituiçōes de ensino de l' e ou 2' grau ou do ensino superior. Como esta sistemática faz medidas estanques e parciais, nāo acompanhando o desenvolvimento do aluno, foi introduzido no sistema universitário oficial, o método de avaliação por conceitos (Reforma Universitária - década de 70) que se traduz na utilização das letras $A, B, C, D, E$. Diferentemente da anterior, a avaliação por conceito deve ser permanente, seqüencial e cumulativa. Assim, o aluno deve ser permanentemente acompanhado e "seu conceito" vai representando a sua real posiçāo frente ao desenvolvimento da matéria. Desta forma, a ultimo conceito atribuído ao aluno representa a sua posição final no processo de avaliação. Como tudo isso é muito difícil e não estavamos preparados para a adoção dessa nova sistemática, o que se vê (ainda) e a atribuição de letras como se fossem números. E se faz a media dessas letras (!?!). Ora, assim, se alguma coisa mudou, foi para pior.

- a extensão, seqüência e composição curricular - requerem uma agilidade e dinâmica próprias e permanentes, que permitam a eliminação e ou a introdução de novas disciplinas e, ou conteúdos. Isto irá determinar, automaticamente a sua extensão em anos, a sua atualização e consequentemente o seu diferencial frente aos demais recursos.

- o treinamento isolado, exclusivamente por matérias, sem atividades integradoras;

- a carga horária de trabalho dos alunos em cursos de graduação. Uma característica genérica dos cursos de Odonto e o grau de absorçáo do tempo dos alunos, com aulas teóricas e práticas pela manhã e tarde em turnos completos. Falta uma adequada previsão de disponibilidade de tempo para estudo, consultas em biblioteca e autotreinamento; sem o que torna-se dificil consolidar os novos conteúdos constanternente introduzidos.

- a insatisfaçāo docente com os baixos sa l arios e com a mutabilidade de critérios que se verifica no Ministério da Educação que a cada mudanca ministerial parece esquecer ou desconhocu todh a historia evolutiva sobre pesquisa e pósgraduação da Universidade Brasileira. - a falta de retroalimentaçäo do sistema com a participação dos egressos, já mencionada. 
- Os regimes de trabalho dos docentes: necessidades, cumprimento, tipos novos ...

— A importância da prática ( clínica) para os docentes.

- Aprimoramento curricular voltado à formação do dentista genera l ista (clínico).

Problemas Pós-graduados da formação profissional

Ebem reconhecido por todos que o ensind educação, transformou-se, no mundo atual, em uma das maiores fontes arrecadadoras. Um grande negócio! Em sua edição de abril/maio deste ano, o Jornal do CFO 6, 7 apresentou um suplemento especial sobre o ensino Odontológico com a ilustrativa informação de que temos, no Brasil, 126 cursos de especialização executados por faculdades e outros 125 executados por outras entidades. Pode-se inferir que estes últimos não tem vínculos de origem com o processo ensino-aprendizagem. Caso o "negocio" não fosse verdadeiramente bom, essas entidades não abandonariam suas origens, suas atividades originais; para virem competir diretamente com quem esta estruturado, preparado e a quem compete trabalhar com os temas e assuntos do ensino-aprendizagem. Seria muito interessante se pudéssemos observar suas reaçóes caso as faculdades começassem também a, por exemplo, fabricar produtos e comercializá-los diretamente, dentre outras atividades que dissessem respeito a tais grupos.

A explosão demográfica mundial associada ao desejo natural de conquista de " um lugar ao sol”, requer capacitação, preparo, seja em que área for. Estas aspirações reforçam ainda mais o crescente poder daquelas instituições que passaram a se envolver com a educação. E aí, encontramos de tudo, desde a mais perfeita intenção e condições para bem preparar as pessoas, até o maior despreparo e a busca do lucro fácil e descompromissado. Do ótimo ao pior! Por isso, é preciso definir com clareza, ou redefinir, ou analisar permanentemente, ou controlar alguns pontos importantes do sistema de pós-graduação como:

— finalidades do sistema de pós-graduação:

- aprimorar a prática

- preparar o docente e

- formar o pesquisador

- categorização dos tipos de cursos conforme as finalidades definidas:

- para aprimorar a prática: - em geral (cursos de atualizaçāo, extensão...) e especialização: entendida esta como a capacitação profissional mais alta para a prática, sem que qualquer outra a supere neste sentido. Nāo requer o estudo acessório de atividades relacionadas ao ensino e a pesquisa.

t'. a preparar o docente: - mestrado: o lestre necessita ter o preparo lécnico-profissional do especialista ( este preparo do especialista, como se viu deve ser insuperável para a atuação profissional), e aprofundarse no estudo de matérias como pedagogia, didática, administração, filosofia etc. que significam aquilo que é necessário para ser um professor. Pode, ainda, ser introduzido na arte da pesquisa.

- para formar o pesquisador:doutorado. Para a formação do pesquisador devem ser estudados conteúdos relacionados ao desenvolvimento e prática da investigação cientifica. Em qualquer destes cursos ( mestrado e doutorado) que representam a pós-graduação senso estrito, não há que reestudar os conteúdos do nível anterior, na forma de uma revisão, como costuma acontecer. Por sinal, este aspecto da retomada de conhecimentos anteriores, tem se mostrado por demais exagerado, gastando tempo precioso, aumentando custos e não exigindo o devido nível de competência do nível anterior. $\mathrm{Ha}$ que tê-los como pré-requisitos.

- as entidades executoras dos cursos conforme a categorização e as finalidades: requisitos mínimos para credenciamento e sistemas de recredenciamentos periódicos de controle envolvendo: entidade controladora, corpo de analistas e demais requisitos indispensáveis ao bom funcionamento do sistema para todos os cursos, nos moldes existentes para a pósgraduação senso estrito, mestrado e doutorado.

\section{Hoje, em Porto Alegre, temos:}

- FACULDADES desenvolvendo cursos de Doutorado, Mestrado, Especialização, Extensão, Aperfeiçoamento e outros cursos diversos. ABO E SOBRACOM desenvolvendo cursos de Especialização e outros diversos. SOBRACID, INODON, DENTARIA KLYMUS com cursos diversos. Cursos diversos por grupos diversos. Vale lembrar a desavença que se desenvolveu em S. Paulo, entre APCD e CFO, com relação a fiscalização de cursos. 0 CFO entende que deve fiscalizar os cursos de especialização, contra o que se insurge a APCD. Pessoalmente entendo que, como cabe no CFO (através dos CROs), emitir os certificados dos especialistas e credenciar os cursos, também lhe cabe a fiscalização. Acho ainda mais, que algum órgão ou entidade ( $e$ pode ser o próprio CFO) deveria exercer uma rigorosa fiscalização sobre todos os demais cursos. Quem dá? Como dá? Em que condições? E se isso já for da competência de algum organismo, que seja mantido, ou reativado e informado à categoria. Todos temos acompanhado as noticias da enorme quantidade de cursos caça-níqueis que se desenvolvem pelo Brasil à fora, prejudicando colegas das mais diferentes maneiras, desde a financeira até a própria formaçāo cultural.

\section{PROBLEMAS DA PRATICA PROFISSIONAL}

Os problemas da prática profissional certamente são os mais conhecidos de todos os Cirurgiões-Dentistas, visto que são sentidos diariamente. Juntos, certamente formularíamos uma listagem muito maior do que os ítens que, a seguir, servirão para exemplificar este tópico:

- custos dos materiais; - custos dos equipamentos; - controle de qualidade de materiais: vencidos, danificados, fornecidos a menos; - manutenção do consultório: os gastos fixos e os eventuais; treinamento do pessoal auxiliar e manutenção ou atualização do treinamento; - dificuldades em adquirir materiais de ultima geração no mercado portoalegrense; - ampliação da clientela; manutenção da clientela; - o imposto de renda; 0 o trabalho isolado - que e cada vez mais antieconômico, enquanto o trabalho associado vai se tornando numa perspectiva mais adequada ao exercício da clínica privada; - a formação profissional" e sua manutenção.

E, mais, como bem lembra o Prof. Henrique Teitelbaum - "convênios e credenciamentos que não respeitam nem as condições de trabalho e muito menos os valores a serem pagos pelos procedimentos; a pesadíssima carga tributária; a crise econômica que retira os pacientes dos consultórios e a grande maioria dos profissionais, em todo o país obrigada a se submeter em trabalhar com remuneração positivamente aviltante."

\section{PROBLEMAS COMUNS A FORMAÇĀO EÀ PRÁTICA}

Alguns temas importantes, não ficam bem enquadrados quando vistos somente do ponto de vista da formação ou então da prática profissional. Eles se situam medianamente, entre as duas situaçōes, ou então, tendendo para uma delas. Estas situaçōes envolvem, consequentemente, as diferentes instituiçōes que tratam desses aspectos.

Alguns exemplos desses problemas e que em seqüência pretendemos de detalhar dizem respeito a: - formação dos generalistas,

- a odontologia preventiva e - a relação CD / HABITANTES.

\section{1. - A necessidade de formarmos profissionais generalistas e a realidade do preparo e da valorização das especialidades.}

Primeiramente e importante salientar que é muito bom contarmos com um sistema de pós-graduaçāo que permita a formaçāo de especialistas nos mais diferentes aspectos profissionais. Essa formaçāo deverá. ser cada vez mais intensiva, embora, talvez nāo tanto extensiva. Em outras palavras, mais aprofundada mas não para tantos profissionais. De qualquer forma, a especialização até que vai bem, e não é o problema imediato. 0 problema imediato é o da formação do generalista, que deveria ser de uma extensão máxima. Isso vai mal! Â semelhança da Medicina, a Odonto logia não tem conseguido desenvolver este processo a 
contento. Ao longo da vida, temos ouvido manifestaçōes favoráveis à formação deste tipo de profissional, o clínico ou generalista. Mas, atitudes, compromissos, mudanças nesse sentido, são muito raras. A própria estrutura curricular dos cursos de graduação se vale dos nomes das especialidades para elencar suas disciplinas. Quase inexistem clínicas acadêmicas generalistas que reproduzam o real ambiente de trabalho do clínico, onde ele atenda um paciente integralmente em suas necessidades e não execute apenas uma atividade especifica, nâo contextualizada. É claro que em momentos iniciais do curso poderá ser necessário trabalhar alguma atividade independentemente - o que não pode é ser sempre assim! Os próprios ambulatórios das faculdades também necessitariam de um sistema diferente de utilização, com os alunos fixos e os doentes de "diferentes especialidades", vindo atendê-los integradamente. Ao contrário do que se vê hoje, com os ambulatórios e os professores das "especialidades" esperando por alunos e pacientes para prestar aquele ensino ou atenção especializados. Isso consolida mais ainda a especificidade do ambulatório e dos docentes como sendo propriedades da "disciplina $x$ ", o que é igual a " especialidade x ". Por outro lado, para o próprio exercício profissional, o dentista só se pode anunciar como clínico ou generalista, muito recentemente. $E$ isso com o agravante de ser categorizado como aquele profissional que realizou apenas o curso de graduaçāo - como se nunca mais tivesse estudado - sendo o estudo uma prerrogativa dos especialistas. Com todas estas dificuldades, entraves, desestímulos e despreparo, quem vai querer ser clínico? Parece ser difícil observarmos que, nos tempos atuais, para o recém formado, é na clínica que estão as mais amplas oportunidades de trabalho. Acredito que a atividade clínica ou generalista só ocupará seu devido e merecido espaço, quando conseguirmos transformá-la em algo semelhante a uma especialidade odontologica. Isto, de longa data está sendo tentado resolver pelos cursos de medicina, que passaram pelas experiências com a Residência em Medicina Interna e mais recentemente com a Clínica Médica - e - que não deixam de buscar novas soluções para o assunto. Por que não criarmos também uma Especialidade para a Clínica Odontológica? Não tenho dúvidas de que as demais especialidades cresceriam ainda mais com isso. Seria bom para todos. Quanto mais crescer a atividade generalista mais crescerão as especialidades.

\section{2. - O desvirtuamento da Odontologia Preventiva.}

0 CFO aboliu a especialidade odontologia preventiva ( não poderia ter assumido, essa especialidade, o caráter da especialização clínica?) porque "todos os dentistas deveriam ser preventivistas “. Não se justificava assim, a existência de uma especialidade. Todos conhecemos as diferenças entre o dever e o ser . Passados cerca de 15 anos, a grande maioria das faculdades de Odontologia tem poucos conteúdos de Odontologia Preventiva, pouca carga horária de ensino de prevençāo, número reduzido de docentes e baixa produção cientifica. Saliente-se a honrosa excessão da Fac. Odonto da UFRGS. Isto ajuda a entender porque continua a situação já tão antiga de falar-se tanto e bem da prevençáo e se fazer tão pouco com ela. Em um estado como o descrito acima, não é de se estranhar que alguns setores da indústria odontológica tenham se aproveitado do interesse teórico pela prevenção, para projetarem uma prática consumista por dentistas e pacientes que imaginam, até, estarem fazendo a melhor prevenção do mundo. Isto, quando não recebem o "certificado de aprovaçãa" de alguma entidade da classe odontológica. $\mathrm{Na}$ verdade os princípios básicos da prevenção ainda continuam mal utilizados e mais do que nunca é preciso revigorá-los. Em nosso meio, saudáveis exceções se verificam com o desenvolvimento das " clínicas de bebês "e serviços do tipo do " Serviço de Odontologia da Prefeitura de P.Alegre".

\section{3. - A relação CD/Habitantes e a contínua abertura de novos cursos de odontologia e ou aumento de novas vagas em cursos jáa estabelecidos.}

Poucos países tem conseguido proporcionar uma atenção odontológica satisfatória para sua população 3,9 .0 modelo de atenção curativa, que ainda domina, fez, com que houvesse um grande aumento no numero de dentistas naqueles países onde a carie dental era mais endêmica, isto é, nos países mais desenvolvidos. Esse aumento do número de profissionais se verificou tanto ao nivel das clínicas privadas como nos serviços assistências (públicos e privados) ${ }^{3}$. No início da década de 80 , os gastos efetivados com a assistência odontológica se tornaram mundialmente tão elevados que as organizações deram-se conta de que um antigo axioma que dizia: "QUANTO MAIS DENTISTAS, MELHOR SAÚDE BUCAL" estava totalmente equivocado e deveria ser substituído por outro: "QUANTO MAIS PREVENCAO, MAIS E MELHOR SAÚDE BUCAL". Desde uma vez que o maior número de profissionais não significava melhor saúde para a população, iniciou-se o desenvolvimento sistematizado de observações sobre qual a relação que se traduzia em um adequado nível de atenção. Quantas pessoas um dentista era capaz de atender eficazmente? No início da década de 80, a Organização Mundial da Saúde definiu esta re lação em $1 \mathrm{CD}$ para 1.500 habitantes5. Na década anterior (de 70), Mario Chaves $^{3}$ citando estudos norte- americanos, mencionava como muito boa uma relações de menos de 2.000 hab. por CD. Mencionava, ainda, que os USA apresentavam-se com uma relação de $1 / 1.700$ e lembrava estudos de Wisan que apontava em áreas metropolitanas dos USA, a relação de $1 / 587$. Normalmente, o número de dentistas existentes em um certo pais, em um instante dado, é determinado pela demanda da população aos serviços odontológicos. E essa demanda vai safrer a influência dos fatores sócio-econômicos com todas as suas nuances e particularidades. Genericamente, populaçōes ricas demandam muito e populaçōes, quanto mais pobres, menos demandam. Vejamos como se desenvolve o quadro nacional . A evolução da relação de habitantes por $\mathrm{CD}$, por Regiōes, no Brasil, nos últimos dez anos está apresentada na Tabela $\mathbf{I}$. Observe-se a baixa relação existente nas Regiōes Sudeste (cm especial em S.Paulo) e Sul (em especial RS ). Os dados da Regiāo Centro-Oeste sofrem uma influência acentuada da concentração de profissionais em Brasília.

\section{TABELAI}

Evolução da relação habitantes/CD do Brasil

\begin{tabular}{|l|c|c|}
\hline & 1987 & 1996 \\
\hline Brasil & 1500 & 1142 \\
\hline Região Norte & 3740 & 3140 \\
\hline Regiāo Nordeste & 3050 & 2424 \\
\hline Região Sul & 1500 & 1153 \\
(RS)-CRO/98 & - & 1113 \\
\hline Região Centro-Oeste & $1000(?)$ & 1140 \\
\hline Regiaao Sudeste & 1050 & 769 \\
(SP)-APCD/98 & - & 650 \\
\hline
\end{tabular}

Fontes: M. Saúde - $1988^{5}$ CFO- $1996^{8}$ CRO/RS - $1998^{4}$ APCD - 1998

Ao mesmo tempo em que se analisa estas relações, é bom lembrarmos que, no mesmo periodo (1987 a 1996 ) o total de CinurgiōesDentistas aumentou de 93.500 para 139.110 como fruto do aumento do número de formandos ao ano, que passou de 5.500 para $8.236 .{ }^{8}$ No ano de 1998, segundo o CFO, ${ }^{8}$ já somos 146.379 CDs. Este acelerado aumento no número de Cirurgióes-Dentistas, manifesta-se também presente em relação ao crescimento populacional, conforme se pode observar na taxa de crescimento anual dos dois segmentos (Gráfico I ) divulgada pelo Conselho Regional de Odontologia do RS com dados de dezembro de $1996 .{ }^{4}$

\section{GRÁFICO I}

Taxa de Crescimento Anual (\%)

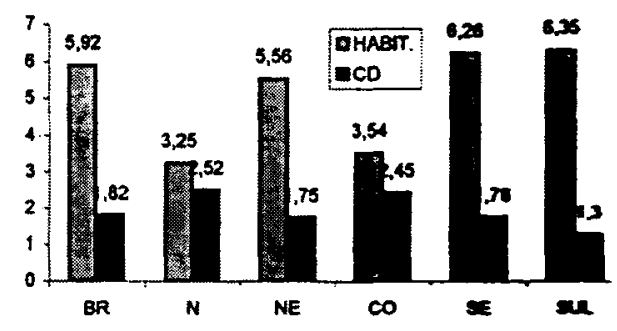

Salienta o CRO 4 a desequilibrada retopio entre profissional e habitantes, tanto no plano nacional como regional, em funçào da distribuição tanto dos profissionais como das cursos de Odontologia.

É preciso não esquecer que coste dado da 
relação de habitantes por $C D$, não significa pacientes disponíveis para cada $C D$. Veja-se que: - nos USA (1957): a população tratada correspondia a $36 \%$ da população em geral ${ }^{5}$. no BRASIL (1996): a população tratada é $17 \%$ da população em geral, sendo que:

$-12 \%$ foram atendidos na clínica privada e $5 \%$ nos serviços assistências ${ }^{8}$

Assim, a relaçáo brasileira de 1.142 hab. $/ C D$, na prática, significa uma outra verdade que é a de 194 pessoas atendidas/ $C D$, sendo 137 nas clínicas privadas e 57 nos serviços assistências. Veja-se que incongruência: enquanto $83 \%$ da população brasileira está. sem atendimento, por um problema estrutural da atenção à saúde (com uma demanda potencial e latente imensa ) e - há falta de pacientes na clínica privada devido ao desaquecimento econômico e de empregos para os dentistas realizarem atenção comunitária, o que aprofunda a crise assistencial; - o número de dentistas aumenta contínua e rapidamente conotando uma pletora profissional. Isto pode ser bem observado na Tabela II

TABELAII

Evolução da abertura de novos cursos de odonto no Brasil

\begin{tabular}{|c|c|}
\hline ANO & $N^{\circ}$ CURSOS \\
\hline 1900 & 4 \\
\hline 1920 & 12 \\
\hline 1940 & 14 \\
\hline 1960 & 32 \\
\hline 1980 & 63 \\
\hline 1986 & 74 \\
\hline 1996 & 90 \\
\hline
\end{tabular}

Fonte: M.Saúde ${ }^{5}$ CFO $^{8}$

Em 1986, com 74 cursos, já superávamos USA e Canadá juntos ou qualquer outro país. ${ }^{5}$ No ano de 1998, novos cursos foram abertos: ${ }^{8}$ Torres

- no RS (3): Cachoeira, Santa Cruz e

- em outros estados (6): Tocantins, Minas Gerais, Espírito Santo, Mato Grosso e Pará. Ainda no ano de 98, o Conselho Nacional de Educação negou o prosseguimento de 26 processos que pediam autorização de funcionamento de novos cursos ao longo do país. Mas, autorizou o prosseguimento de outros 16 cursos que até poderão estar funcionando no próximo ano. TODOS estes fatos dizem respeito a entidades particu lares". ${ }^{8}$ Assim, a partir de 2001 estaremos recebendo mais de 400 novos colegas ao ano, que se somarão aos outros 8.236 formados anuais (seremos 8.636/ ano). Nessa mesma ocasião seremos cerca de 180.690 colegas ou mais. Enquanto isso o Ministério da Educação continua autorizando a abertura de novos cursos à sua vontade, utilizando critérios desconhecidos, atendendo interesses político-econômicos e desconsiderando os reclamos das entidades da classe

R. Fac. Odontol., Porto Alegre, v. 40, n. 1, p. 03-07, set. 1999
Odontológica. 0 CFO tem desenvolvido uma atuação incisiva a esse respeito, mas nada tem conseguido de efetivo. Entende o Sr. Ministra da Educação que " 0 mercado será o regulador dos bons profissionais e das boas escolas. Como se ensino e profissão que trata da saúde fossem mercadorias que se compram em supermercado". Como se tais componentes ainda não bastassem para a certeza de que algo deve ser feito, pode-se observar também a peculiar demanda aos cursos de Odonto. Considerada poeticamente, como a última das profissōes liberais, i. e, aquela que ainda pode ser exercida independentemente de emprego ou assalariamento, a Odontologia vem se constituindo cada vez mais em uma forte atração aos regressos do $2^{\circ}$ grau. 0 Jomal Odonto Noticias, ${ }^{2}$ apresenta uma comparação entre a procura pelo curso de Odonto e o de Medicina (Tabela III).

\section{TABELA III}

Comparação entre a procura pelos cursos de Odonto e Medicina.

\begin{tabular}{|l|c|c|}
\hline & MEDICINA & ODONTOLOGIA \\
\hline Faculdades & 88 & 90 \\
\hline Vagas & 8500 & 8300 \\
\hline Candidatos & 200000 & 250000 \\
\hline Proporção & $1 / 23$ & $1 / 30$ \\
\hline Formandos/Ano & 8150 & 8000 \\
\hline
\end{tabular}

Fonte: Odonto Notícias ${ }^{2}$

ORA, tendo em vista: assistida;

- que a população está cada vez menos

- que cresce desmesuradamente a formação de dentistas;

- que não são criados novos postos de trabalho (empregos) para os CDs e - que a situação econômica da população se apresenta cada vez mais deteriorada, impedindo seu acesso às clínicas privadas; • teme-se pela formação de uma legião de profissionais desempregados e ou desocupados, dentre outras tantas possibilidades nada animadoras.

Isto não é uma visão pessimista! Isto é a tradução objetiva da seqüência de como os fatos vem se desenvolvendo no Brasil.

É PRECISO INTERESSAR-NOS E INTERESSAR AOS ÓRGÃOS DA CLASSE ODONTOLÓGICA E INSTITUIÇŌES DE ENSINO SUPERIOR PARA 0 MAPEAMENTO E PERFEITA DEFINIÇĀO DOS NOSSOS PROBLEMAS. ISTO PODERÁ SER 0 INÍCIO PARA MELHORARMOS AS CONDIÇÓES DE SAÚDE DE NOSSA POPULAÇĀO E AS CONDIÇÕES DE TRABALHO PARA OS NOSSOS JOVENS ATUAIS E FUTUROS CIRURGIŌES-DENTISTAS.

\section{REFERÊNCIAS BIBLIOGRÁFICAS}

1. BARROS, E.R.C. de - Formaçāo Acadêmica e Prática Profissional. R. Fac. Odont Porto Alegre, v.25: $55.59,1983$
2. CAUDURO,R. Comparação entre a procura pelo Curso de Odonto e o de Medicina. J Odonto Noticias, n'61, 1997/98.

3. CHAVES, M.M. Odontologia Social. 2ed. Rio de Janeiro: Labor do Brasil, 1977. 448p.

4. CONSELHO REGIONAL DE ODONTOLOGIA DO RS. Desequilibrada Relação entre Profissional e Habitantes. Jornal do CRO/RS, Porto Alegre. mar. $1998.8 \mathrm{p}$.

5. BRASIL: MINISTERIO DA SAÚdE. Perfil da Odontol ogia Brasileira. Documento Técnico 01 i 88 , maio de 19SS, 33p.

6. PETRELLI, Eros Cursos de Especialização no Brasil. Suplemento Especial de Ensino Odontológico. CFO, Abr/Mai 1998, p.l.

7. 0 MEC e a Odontologia: o caos da Profissão. Suplemento Especial de Ensino Odontológico. CFO, Abr/Mai 1998, p.2 e 3.

8. et alii - Criação de Novos Cursos de Odontologia Relatório do CFO. Dez 1996. 13p.

9. PINTO, V.G. Saúde Bucal: Odontologia Social e Preventiva. São Paulo: Santos, 1989.415p.

10. TEITELBAUM, H. Editorial. Jornal da $A B O$ Nacional, maio/junho, 1998. 